\title{
Yttrium-90 radioembolization for hepatocellular carcinoma in hepatitis B: commentary on a 103-patient Asian cohort
}

\author{
Laura Kulik $\cdot$ Riad Salem
}

Received: 15 May 2014/ Accepted: 25 June 2014/Published online: 23 July 2014

(C) Asian Pacific Association for the Study of the Liver 2014

Y90 radioembolization [also known as selective internal radiation therapy (SIRT)] is recognized as a safe and effective therapy for hepatocellular carcinoma (HCC), with a particular role for Y90 in patients with large tumors and/ or portal vein thrombosis (PVT). Studies from Europe and the United States, comprised of 776 patients in aggregate, have demonstrated comparable results when taking into account cohort differences in terms of baseline Child-Pugh classification and tumor stage defined by the Barcelona Clinic Liver Cancer system (BCLC) [1-4]. These Western studies included patients predominately with hepatitis $\mathrm{C}$ and/or alcohol as the underlying cause of liver disease with limited numbers of patients with hepatitis B virus (HBV) (9-30\%).

$\mathrm{HBV}$ is the leading cause of HCC worldwide, with over $50 \%$ of all causes of $\mathrm{HCC}$ attributable to HBV. While there is convincing data from the REVEAL study that the risk of HCC is impacted by the height of the HBV viral load (VL), there has not been conclusive data that achieving an undetectable HBV VL negates the risk of eventual HCC development. This is hypothesized to be related to the integration of cccDNA into the host DNA with a carcinogenetic capacity via genetic instability. Clinical-pathologic differences have been reported between HBV versus Hepatitis $\mathrm{C}$ virus (HCV), the former being more commonly associated with larger tumors,

L. Kulik

Division of Hepatology, Department of Medicine, Northwestern University, Chicago, IL, USA

\section{R. Salem $(\square)$}

Section of Interventional Radiology, Department of Radiology, Northwestern University, 676 N. St. Clair, Suite 800, Chicago, IL 60611, USA

e-mail: r-salem@northwestern.edu younger age and lower cirrhosis rates [5]. Other single center retrospective reports have sought to determine if a difference exists in outcomes with various therapeutic options. Viral etiology was not found to have an impact on outcome among patients treated with transarterial chemoembolization (TACE) [6]. However, the etiology of disease has been apparent in orthotopic liver transplant (OLT), with a significant decrease in overall survival (OS) in HCV due to recurrent HCV post-transplant [7]. Systemic therapy with sorafenib was associated with shorter median OS among Asian patients relative to a Western cohort; however, there was a similar degree of survival benefit associated with sorafenib relative to placebo (hazard ratios 0.69 and 0.68 , respectively) $[8,9]$.

The experienced team from Singapore has reported a retrospective analysis of 103 Asian patients with nearly half $(47.6 \%)$ of the patients with HBV-induced HCC treated with Y90 [10]. The tumor characteristics were comparable to the Western cohorts (Table 1). Safety and tolerability were also similar to other cohorts. While the authors demonstrated a comparable median OS of 14.4 months, the time-to-progression (TTP) of 5.3 months was shorter. Progression (using RECIST 1.1 at 3 months after therapy) was available in only half of the entire cohort (potentially affecting the results and lower response rate). Nonetheless, it is of interest that progression was not seen in the treated lesion(s) and the analysis was limited to the first Y90 administration, demonstrating excellent local tumor control; such a pattern of metastases and the high local control rates have been reported previously [11, 12]. However, $38 \%$ of disease control was due to stable disease which, among TACE cohorts, has been found to predict worse outcomes compared to those with complete/partial response [13]. The use of RECIST 1.1, without taking into account presence of necrosis, makes it impossible to 
Table 1 Clinical experience with radioembolization in HCC

\begin{tabular}{|c|c|c|c|c|c|}
\hline & $\begin{array}{l}\text { NW }(n=291) \\
\text { Single center glass }\end{array}$ & $\begin{array}{l}\text { Essen }(n=108) \\
\text { Single center glass }\end{array}$ & $\begin{array}{l}\text { European }(n=325) \\
\text { Multicenter resin }\end{array}$ & $\begin{array}{l}\text { Milan }(n=52) \\
\text { Single center glass }\end{array}$ & $\begin{array}{l}\text { Asian }(n=103) \\
\text { Single center resin }\end{array}$ \\
\hline \multicolumn{6}{|l|}{ Patient characteristics } \\
\hline $\mathrm{CP} \mathrm{A} / \mathrm{B} / \mathrm{C}(\%)$ & $45 / 52 / 3$ & $77 / 22(\leq 7) / 0$ & $82 / 18 / 0$ & $83 / 17(\leq 7) / 0$ & $59 / 38 / 3$ \\
\hline BCLC A/B/C/D (\%) & $17 / 28 / 52 / 3$ & $2 / 47 / 51 / 0$ & $16 / 27 / 56 / 1$ & $0 / 33 / 67 / 0$ & $1 / 27 / 69 / 3$ \\
\hline Mean tumor size $(\mathrm{cm})$ & 7.0 & - & - & 5.6 & 8.8 \\
\hline Multifocal (\%) & 73 & - & 76 & 69 & 81 \\
\hline PVT (\%) & 43 & 31 & 23 & 67 & \\
\hline Extrahepatic mets (\%) & 16 & 30 & 9 & - & 12 \\
\hline \multicolumn{6}{|l|}{ Outcomes } \\
\hline \multirow[t]{5}{*}{ Overall survival (months) } & CP A: 17.2 & CP A: 17.2 & CP A: - & CP A: - & CP A: 21.7 \\
\hline & CP B: 7.7 & CP B: 6.0 & CP B: - & CP B: - & CP B: 7.1 \\
\hline & BCLC A: 26.9 & BCLC A: - & BCLC A: 24.4 & BCLC A: - & BCLC A: - \\
\hline & BCLC B: 17.2 & BCLC B: 16.4 & BCLC B: 16.9 & BCLC B: 18 & BCLC B: 23.8 \\
\hline & BCLC C: 7.3 & BCLC C: not reached & BCLC C: 10.0 & BCLC C: 13 & BCLC C: 11.8 \\
\hline \multirow[t]{3}{*}{ TTP (months) } & 7.9 & 10.0 & - & 11 & 5.3 \\
\hline & CP A 10.8 & & & & CP A 5.7 \\
\hline & CP B 8.4 & & & & CP B 4.6 \\
\hline \multicolumn{6}{|l|}{ Adverse events } \\
\hline Abdominal pain $(\%)$ & 23 (grades 1-2) & 56 (grades $1-2)$ & 27 (all grades) & 6 (grades 3-4) & 12 \\
\hline GI ulcers $(\%)$ & 0 & 0 & 3.7 & 0 & 1.9 \\
\hline \multicolumn{6}{|l|}{${ }^{a}$ Salem et al. [1] } \\
\hline \multicolumn{6}{|l|}{ b Hilgard et al. [2] } \\
\hline \multicolumn{6}{|l|}{ c Sangro et al. [4] } \\
\hline \multicolumn{6}{|l|}{${ }^{\mathrm{d}}$ Mazzaferro et al. [3] } \\
\hline e Yu et al. [10] & & & & & \\
\hline
\end{tabular}

speculate if less favorable outcomes would be anticipated in the radioembolization cohort with stable disease. Additionally, nearly $20 \%$ of patients had TACE prior to Y90. It is conjecture that such patients may have derived less of a robust response if the timing of sequential Y90 was too short to permit vascular recanalization post-TACE.

The authors admit that their data preclude the ability to correlate the impact of viral etiology on the outcomes in patients treated with radioembolization. In the multivariate analysis, HCV was associated with improved OS (hazard ratio $=0.13$ ), and furthermore there was a noted trend of HBV leading to a lower OS compared to non-HBV patients (12.4 vs. 18.1 months, $p=0.76$ ). The authors did not report if there were a greater proportion of $\mathrm{HCV}$ patients that eventually underwent OLT. While TTP was censored after receipt of 1 Y90 session, and was likely impacted by the short imaging follow-up time, OS was not, potentially resulting in a confounding effect of post-progression treatment.

Liver parameters (bilirubin, albumin) were independent predictors of OS, both of which can be impacted by the degree of underlying liver disease, HCC progression, and treatment decision in terms of radiation dose and degree of treated liver. It is not stated if there was a difference in these laboratory values in $\mathrm{HBV}$ versus $\mathrm{HCV}$; $\mathrm{HCV}$ can be associated with an overall greater degree of liver impairment due to HBV generally being able to be suppressed with potent anti-viral agents. Due to the retrospective nature of this study, the authors were also not able to ascertain if active viral replication, specifically $\mathrm{HBV}$, impacted OS. The REVEAL study clearly showed a biological gradient of HBV viral load and ALT levels in the risk of developing cirrhosis and HCC. Whether this "gradient" exists once a patient develops HCC is less clear. Another clinical consideration that is becoming more apparent among patients with $\mathrm{HBV}$ is the co-existence of hepatitis D (HDV) associated with a more aggressive hepatitis and increased HCC risk [14]. Other factors that could have an impact in HBV-induced hepatocarcinogenesis include genotype, mutations and antiviral therapy. In future analyses, examining outcomes in HCC with various therapeutic modalities, stratification based on the presence of active $\mathrm{HBV}$ replication, including $\mathrm{HBsAg}$ titers and HDV status, may help decipher the heterogeneity in outcomes observed in many studies.

Mortality was predominately related to tumor progression $(84.6 \%)$; however, the majority of disease progression 
was related to development of new lesions consistent with intrahepatic metastasis despite disease control of $100 \%$ in the targeted lesion(s). Inarrairaegui et al. [15] reported that OS was significantly affected by the development of new lesions within the treatment area at 3 months in advanced HCC treated with Y90 (19 vs. 7 months, $p=0.002$ ), leading the authors to conclude that survival was dependent on biological aggressiveness of the tumor. The authors in this study did not provide details as to whether the new lesions were within the treated field. This leads to the question of whether combining a systemic agent with local regional therapy would lead to augmentation of tumor control. Unfortunately, this approach has led to conflicting results in the pre-OLT setting (Y90 + sorafenib) and in BCLC B (TACE/drug-eluting beads + sorafenib), with the most encouraging results among a HCV alone cohort [1620]. However, it is apparent that, with tumor progression, many patients develop hepatic decompensation, limiting the ability to initiate sorafenib [21,22]. These clinical realities and the interaction between treatment/progression/liver function potentially suggest the earlier use of systemic agents prior to the development of tumor progression when synthetic function is maintained [21]. Side-effects and cost would need to be factored into such decisions. Ongoing controlled trials will eventually answer this very important clinical question.

These data contribute to the growing body of clinical evidence supporting Y90 in HCC with OS rates comparable to Western series. The question of whether HBV has worse outcomes relative to HCV in general and with specific therapies such as radioembolization remains speculative. Certainly, with the advent of direct acting anti-viral for $\mathrm{HCV}$ and response rates exceeding $90 \%$, it is hypothesized that outcomes in $\mathrm{HCV}$-induced $\mathrm{HCC}$ will improve, especially post-OLT. This may highlight potential differences in hepatocarinogenesis (and hence prognosis) from $\mathrm{HBV}$ or $\mathrm{HCV}$ and make them more apparent.

\section{References}

1. Salem R, Lewandowski RJ, Mulcahy MF, Riaz A, Ryu RK, Ibrahim S, et al. Radioembolization for hepatocellular carcinoma using Yttrium-90 microspheres: a comprehensive report of longterm outcomes. Gastroenterology 2010;138:52-64

2. Hilgard P, Hamami M, Fouly AE, Scherag A, Muller S, Ertle J, et al. Radioembolization with yttrium-90 glass microspheres in hepatocellular carcinoma: european experience on safety and long-term survival. Hepatology 2010;52:1741-1749

3. Mazzaferro V, Sposito C, Bhoori S, Romito R, Chiesa C, Morosi $\mathrm{C}$, et al. Yttrium-90 radioembolization for intermediate-advanced hepatocellular carcinoma: a phase 2 study. Hepatology 2013;57: $1826-1837$

4. Sangro B, Carpanese L, Cianni R, Golfieri R, Gasparini D, Ezziddin $\mathrm{S}$, et al. Survival after yttrium-90 resin microsphere radioembolization of hepatocellular carcinoma across Barcelona clinic liver cancer stages: a European evaluation. Hepatology 2011;54:868-878

5. Hiotis SP, Rahbari NN, Villanueva GA, Klegar E, Luan W, Wang Q, et al. Hepatitis B vs. hepatitis C infection on viral hepatitisassociated hepatocellular carcinoma. BMC Gastroenterol 2012;12:64

6. Chen BB, Shih IL, Wu CH, Hsu C, Chen CH, Shih TT, et al. Comparison of characteristics and transarterial chemoembolization outcomes in patients with unresectable hepatocellular carcinoma and different viral etiologies. J Vasc Interv Radiol 2014;25:371-378

7. Tandoi F, Ponte E, Saffioti MC, Patrono D, Mirabella S, Lupo F, et al. Liver transplantation for hepatocellular carcinoma within Milan Criteria in patients with Model for End-Stage Liver Disease score below 15: the impact of the etiology of cirrhosis on long-term survival. Transpl Proc 2013;45:2711-2714

8. Llovet JM, Ricci S, Mazzaferro V, Hilgard P, Gane E, Blanc JF, et al. Sorafenib in advanced hepatocellular carcinoma. N Engl J Med 2008;359:378-390

9. Cheng AL, Kang YK, Chen Z, Tsao CJ, Qin S, Kim JS, et al. Efficacy and safety of sorafenib in patients in the Asia-Pacific region with advanced hepatocellular carcinoma: a phase III randomised, double-blind, placebo-controlled trial. Lancet Oncol 2009; 10:25-34

10. Yu et al. Survival and pattern of tumor progression with Yttrium90 microsphere radioembolization in predominantly hepatitis B Asian patients with hepatocellular carcinoma. Hepatol Int 2014. doi:10.1007/s12072-014-9533-9

11. Vouche M, Habib A, Ward TJ, Kim E, Kulik L, Ganger D, et al. Unresectable solitary HCC not amenable to RFA: Multicenter radiology-pathology correlation and survival of radiation segmentectomy. Hepatology 2014;60(1):192-201. doi:10.1002/hep. 27057

12. Senthilnathan S, Memon K, Lewandowski RJ, Kulik L, Mulcahy MF, Riaz A, et al. Extrahepatic metastases occur in a minority of hepatocellular carcinoma patients treated with locoregional therapies: analyzing patterns of progression in 285 patients. Hepatology 2012;55:1432-1442

13. Georgiades C, Geschwind JF, Harrison N, Hines-Peralta A, Liapi E, Hong K, et al. Lack of response after initial chemoembolization for hepatocellular carcinoma: does it predict failure of subsequent treatment? Radiology 2012;265:115-123

14. Wedemeyer H, Manns MP. Epidemiology, pathogenesis and management of hepatitis D: update and challenges ahead. Nat Rev Gastroenterol Hepatol 2010;7:31-40

15. Inarrairaegui M, Martinez-Cuesta A, Rodriguez M, Bilbao JI, Arbizu J, Benito A, et al. Analysis of prognostic factors after yttrium-90 radioembolization of advanced hepatocellular carcinoma. Int J Radiat Oncol Biol Phys 2010;77:1441-1448

16. Kulik L, Vouche M, Koppe S, Lewandowski RJ, Mulcahy MF, Ganger D, et al. Prospective randomized pilot study of Y $90 \pm$ sorafenib as bridge to transplantation in hepatocellular carcinoma. J Hepatol 2014. doi:10.1016/j.jhep.2014.03.023

17. Frenette CT, Boktour M, Burroughs SG, Kaseb A, Aloia TA, Galati J, et al. Pre-transplant utilization of sorafenib is not associated with increased complications after liver transplantation. Transpl Int 2013;26:734-739

18. Truesdale AE, Caldwell SH, Shah NL, Argo CK, Al-Osaimi AM, Schmitt TM, et al. Sorafenib therapy for hepatocellular carcinoma prior to liver transplant is associated with increased complications after transplant. Transpl Int 2011;24:991-998

19. Kudo M, Imanaka K, Chida N, Nakachi K, Tak W-Y, Takayama $\mathrm{T}$, et al. Phase III study of sorafenib after transarterial chemoembolisation in Japanese and Korean patients with unresectable hepatocellular carcinoma. Eur J Cancer 2011;47:2117-2127 
20. Sansonno D, Lauletta G, Russi S, Conteduca V, Sansonno L, Dammacco F. Transarterial chemoembolization plus sorafenib: a sequential therapeutic scheme for HCV-related intermediatestage hepatocellular carcinoma: a randomized clinical trial. Oncologist 2012;17:359-366

21. Memon K, Kulik L, Lewandowski RJ, Mulcahy MF, Benson AB, Ganger D, et al. Radioembolization for hepatocellular carcinoma with portal vein thrombosis: impact of liver function on systemic treatment options at disease progression. J Hepatol 2013;58: $73-80$

22. Memon K, Kulik L, Lewandowski RJ, Gupta R, Ryu RK, Miller $\mathrm{FH}$, et al. Prospective evaluation of patients with early-/intermediate-stage hepatocellular carcinoma with disease progression following arterial locoregional therapy: candidacy for systemic treatment or clinical trials. J Vasc Interv Radiol 2013;24: 1189-1197.e1182 